\title{
Point of Technique
}

\section{An innovative method of electro-cauterization to control bleeding}

\author{
Abdelmoughit Echchaoui ${ }^{1 *}$, Mina Amellal' ${ }^{2}$, Lamin Jaiteh ${ }^{3}$, Malik Boulaadas ${ }^{4}$ \\ ${ }^{1}$ Department of Plastic and Reconstructive Surgery, Ibn Sina University Hospital, Rabat, Morocco \\ ${ }^{2}$ Department of Anatomy, Faculty of Medicine and Pharmacy, Rabat, Morocco \\ ${ }^{3}$ Department of Visceral Surgical Emergencies, Med V University, Rabat, Morocco \\ ${ }^{4}$ Department of Plastic and Maxillofacial Surgery, Med V University, Rabat, Morocco \\ Received: 15 December 2016 \\ Accepted: 16 January 2017 \\ *Correspondence: \\ Dr. Abdelmoughit Echchaoui, \\ E-mail: e.moughit@hotmail.fr \\ Copyright: () the author(s), publisher and licensee Medip Academy. This is an open-access article distributed under \\ the terms of the Creative Commons Attribution Non-Commercial License, which permits unrestricted non-commercial \\ use, distribution, and reproduction in any medium, provided the original work is properly cited.
}

\section{ABSTRACT}

The authors describe a simple and innovative method of managing bleeding by monopolar electrocautery in some critical circumstances such as: the lack of bipolar electrocauter, and the surgeon alone without his assistant, or with one who is inexperienced in surgery.

Keywords: An innovative technique, Bleeding control, Electro-cauterization

\section{INTRODUCTION}

Electro-cauterization (or electrocautery) is a safe procedure used in surgery to control bleeding by bipolar electrocautery or monopolar electrocautery (MEC) to achieve hemostasis of small blood vessels. This reduces blood-loss and prevents exsanguination.

In some circumstances when bipolar electrocautery is not available, electro-cauterization of the source of bleeding is carried out only by monopolar electrocautery (MEC) device and hemostatic forceps, which requires the close coordination between the surgeon and his assistant.

A thorough literature search did not reveal any publication of an alternative way, to the best of our knowledge. We report a simple method of manipulating a MEC by the surgeon alone to promptly and effectively control, by electrocoagulation, any bleeding during the surgical procedure. The technique consists of placing hemostatic forceps between the thumb and index fingers and the MEC being inverted upwards vertically and being placed between the ring and pinky fingers of the dominant hand.

The MEC tip is inserted in between the two lamellas of the forceps in a manner that it touches one of them in order to conduct the electrocoagulation waves to the target tissue (Figure 1).

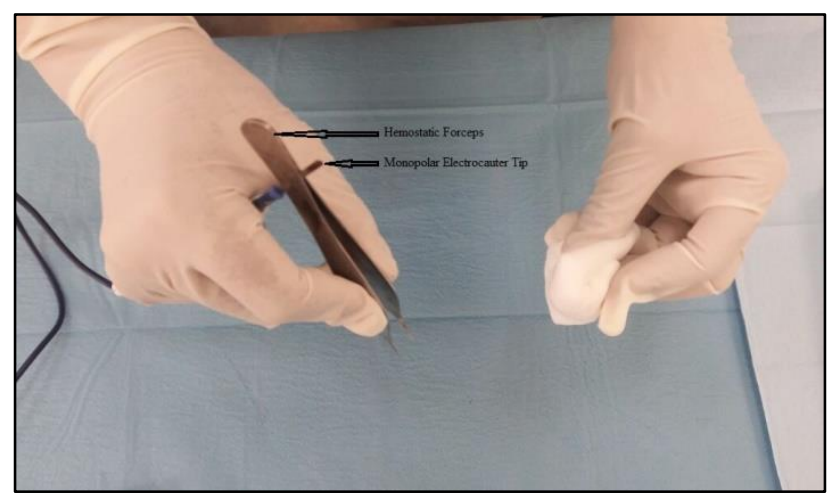

Figure 1: Demonstration of technique. 
The surgeon controls the electric current with the help of the blue foot pedal while the non-dominant hand is used to press swabs onto the bleeding site. This technique has been performed in our institution by several surgeons for at least a decade, and no incidents have been noticed (accidental burning or puncture of the surgeons glove and hand) when performed correctly.

This is a simple, fast, safe and effective method that can be used when a surgeon is operating alone, short of an assistant or with one who is inexperienced in surgery. This technique can help improve operative course, reduce operating time and increase surgical efficiency in certain settings.

Funding: No funding sources

Conflict of interest: None declared

Ethical approval: Not required

Cite this article as: Echchaoui A, Amellal M, Jaiteh L, Boulaadas M. An innovative method of electrocauterization to control bleeding. Int Surg J 2017;4:1145-6. 